\title{
Environmental Education as a Tool for Sustainable Development: Case study of Lekki-Lagos
}

\author{
Chukwu, M. N. ${ }^{1, *}$ and Kadafur, S. J. ${ }^{1}$ \\ ${ }^{1}$ Faculty of Science, National Open University of Nigeria Headquarters, Abuja \\ Corresponding Author:*mchukwu@noun.edu.ng
}

\begin{abstract}
The study examines the strength of environmental education in Lekki-Lagos and its impact on community and grass-root development by considering a targeted sample population comprising some respondents that are living or working in Lekki community in Lagos. A qualitative survey was conducted using participatory observation, interviews, and a structured questionnaire. The questionnaire was validated through peer review and pilot testing. Data collected were summarized and computed using descriptive statistics while a paired t-test and Turkey's HSD test were used for further analysis. Results showed that $92 \%$ of the respondents affirmed that environmental education impacted positively on the community attracting the government, non-governmental and private organizations to help in developing the area through construction of roads, pedestrian bridges, drainages and sea embankments thus reducing flooding, man hour loss due to traffic jam and rate of pollution. There was also a decrease in loss of lives and properties. Investors were attracted to Lekki, reducing poverty and social imbalance thus increasing community development. There is a significant difference between the state of Lekki now and before the intervention of public-private practice in developing the area $(P<0.05)$. It is recommended that the government and other stakeholders should collaborate on a higher scale to enhance developing the unreached communities.
\end{abstract}

Keywords: Environmental education, community development, grass-root, stakeholders, embankments, non-governmental organizations

\subsection{Introduction}

Environmental Education (EE) is a process of impacting awareness and adequate knowledge of the problems and functions of the environment; how to use it wisely and proffer solutions to the current environmental problems (Abubakar, 2010). (Akintunde, 2008) also defined environmental education as "the expansion of the study of ecology; a branch of biology dealing with the interrelationship of living organisms with one another and with their environment". More so, some authors tend to look at the objective of the environmental Education based on the main stream that will affect the environment directly. (Abubakar, 2010) postulated that the fundamental role of Environmental Education (EE) is to give concrete awareness about the environment; how to use it for sustainable development. EE though is of paramount importance, is facing a lot of challenges especially in developing countries like Nigeria (Jekayinfa and Yusuf, 2008).

Environmental sustainability on the other hand involves making decisions and taking actions that are in the interest of protecting the natural environment with particular emphasis on preserving the capability of the environment to support human life. Some authors viewed sustainable development as the ultimate goal of environmental education while others are of the opinion that sustainable development objectives should be added to those of environmental education (Sauvé, 1996). The term sustainable development is widely accepted though there is no agreement on its meaning (Bonnett 2002; Cotton et al 2007; Telfer and Sharpley. 2008, Le Grange 2012a; 2012b)

Nigeria is not excluded from the environmental consequences arising from anthropogenic variables as self-evident in the degradation of the ecosystems, loss of bio-diversity and decrease in agricultural 
produce. In South Eastern region of Nigeria, gully erosion has caused untold damage to numerous farmlands hence many people find it difficult to acquire enough land for agriculture (Gbamenja, 1998). Oil spillage and gas flaring from oil companies have also brought about a lot of destructions in the South - South states of Nigeria. In the Northern fringe, the Sahara Desert is rapidly encroaching on the lands, resulting in shortage of rainfall and poor crop yield each year (Akintude, 2008). The Eastward rapid encroachment of the desert in Northern Nigeria poses threat to sustainable livelihood: for the Niger Delta people, it is 'hell on earth', as cumulative practice of environmental degradation arising from pollution of air, water and land characteristic of oil exploration in Nigeria has made the region a flash point of conflict in the agitation for environmental justice and resource control (Agbu, 2005, and Saka et al, 2007).

Environmental education and protection is inevitable in Nigeria, if actually it wants to achieve environmental sustainability for self-reliance and positive development (Kwale and Wageti, 2005). In this regards, the issue of strengthening Environmental Education in Lekki area of Lagos must imbibe the structure of sustainability. According to Grodzinka-Jurczak et al. (2006), it is an education for sustainable living which enables people to make informed choices that will lead to more sustainable living practices and lifestyles. It is also a process of developing the skills and behavior necessary to understand and accept the relationship between people, culture and the natural environment.

The government and Public-Private sectors still have strong holds of the concept of Environmental education in place just as has been agitated by the millennium development goal suggested by the United Nation and has also carried the mantra today in the rapid expansion of Lekki area of Lagos. These could be related to concept of (Moseley, 2000) that a lifelong interdisciplinary approach aimed at developing people through imposing consciousness of the environment and related issues to those who contribute in solving existing environmental injustices, and also offer formation of new knowledge, skills, attitude, stimulus, personal and social duties and responsibilities. The approach of Environmental education should be interdisciplinary, comprehensive and holistic (Hill, 1999 and Moseley, 2000, Tuncer and Erol, 2007).

Environmental education holds that sustainable development is possible and warns against indiscriminate development that disregards ecological balance. It aims at creating a future society where people are aware of their civic responsibilities and are ready to play useful roles as producers and citizens' conscious of their environmental impact (ICSE, 2000). (Agbogidi and Ofuoku, 2007) established that the environment needs to be sustainably managed in order to fight against poverty, food shortage and homelessness; some of the consequences of environmental degradation.

This paper aims at investigating Environmental education in Lekki, its benefits to the community and the level of difference it has created in the place.

\subsection{Objective}

The objective of this study is to investigate Environmental education as a tool for sustainable development in Lekki community and environ with a view of motivating social groups and individuals to actively participate in identifying and solving environmental problems in the area.

In order to achieve the objective, the following research questions were asked:

i. What kind of environmental problems can be identified in Lekki- Lagos?

ii. To what extent have the problems been solved?

\subsection{Materials and Methods}

\subsection{Study Area}

Lekki city is a natural peninsula in the East of Lagos. It is bounded in the West by Victoria Island and Ikoyi districts of Lagos, in the South by Atlantic Ocean, Lagos Lagoon in the North and Lekki Lagoon 
in the East. The city's South-East which ends around the Western edge of Refuge Island and adjoins the Eastern part of Ibeju-Lekki Local Government Area. The city is with a total area of $755 \mathrm{~km}^{2}$. It is located on the geographical coordinates of $6^{\circ} 29^{\prime} 36^{\prime \prime}$ North, $3^{\circ} 43^{\prime} 14^{\prime \prime}$ East Map (Maplandia, 2017).

A sample of 60 respondents randomly selected from people living or working in Lekki-Lagos was interviewed. Data were collected through observations and personal interviews using structured questionnaire, titled "Environmental Education-Development Questionnaire" (EE-DQ). The questionnaire consists of two sections. The first section focused on the socio-economic characteristics of the respondents while the second section had 18 Likert type items and was designed to assess Environmental Education as a tool for sustainable development. This include functions aimed to indicate (SD); Strongly Disagree, (D); Disagree, (A); Agree and (SA); Strongly Agree. The respondents were personally approached and briefed about the purpose as well as the significance of the study by the researchers. The questionnaire was validated to improve the quality and content before administration. The test-reset reliability scale yielded reliability coefficient of 0.82 . The instrument was thus considered valid and reliable to be used for the study.

The questionnaire was first administered to the respondents (pre-test). Thereafter a post-test was administered a month after an Environmental Education programme was organized in the area. During the post-test, the respondents completed the same questionnaire a second time.

Data collected were summarized and computed using frequency counts and percentages while a paired t-test was used to compare pre-test and post-test means. Turkey's HSD test was used to identify the source of significance difference at 0.05 level of confidence.

\subsection{Results and Discussion}

\subsection{Socio-Economic Characteristics of the Respondents}

The summary of selected socio-economic characteristics of the members of Lekki community is shown in Table 1. The gender distribution of the respondents skewed to the male sex, who accounted for $58.3 \%$ while the female sex accounted for $41.7 \%$. It was observed that $75 \%$ of the respondents are married while only $25 \%$ are not married. This is an indication that most of them are responsible. Respondents within the age bracket of 31 - 40 years recorded the highest count of $56.7 \%$, followed by those of age bracket 21 - 30 years (23.3\%). This showed that majority of the respondents are young and are supposed to be conscious of their environment.

Education attainment and conduct of the Respondents

All the respondents interviewed had both First School Leaving and Senior Secondary School Certificates, while 5, 7, 5, 15, 8 and 6 respondents are holders of Ordinary National Diploma, National Certificate in Education, Higher National Diploma Certificate, First Degree, Master's Degree and Doctor of Philosophy Degree respectively. This showed that most of them are learned and should be ready to learn and welcome new innovations.

\subsection{Influence of Environmental Education on the Community}

Majority (92\%) of the respondents affirmed that Environmental Education programmes promoted the understanding of environmental concepts and issues, thus attracting governmental, non-governmental and private organization to invest towards developing Lekki. They reported that people were moving away from Lekki before the construction of good drainages, roads and pedestrian bridges due to high rate of environmental pollution. According to the respondents, there used to be severe traffic jams before the dualization of the roads and construction of pedestrian bridges which increased the rate of emission of Carbon monoxide gas into the atmosphere. This led to depletion of ozone layer and also made the members of the community susceptible to respiratory tract diseases. Furthermore, they reported an encroachment of oceanic surge to the ecosystem before the construction of sea embankments which led to loss of lives and properties. In addition to this, they use to experience severe flooding before the construction of good drainages leading to high incidence of malaria infection and water borne diseases. 
Table1: Socio-Economic Characteristics of the Community members (Total, $\mathrm{n}=60$ )

\begin{tabular}{llll}
\hline Characteristics & & $\begin{array}{l}\text { Frequency } \\
\text { (f) }\end{array}$ & Percentage \\
\hline \multirow{3}{*}{ Gender } & Male & 35 & 58.3 \\
Age & Female & 25 & 41.7 \\
& 21 - 30 years & 14 & 23.3 \\
& $31-40$ years & 34 & 56.7 \\
& $41-50$ years & 08 & 13.3 \\
Marital status & 51 years and above & 04 & 06.7 \\
Educational attainment & & \\
& Average 40 years & 15 & 25.0 \\
& Single & 45 & 75.0 \\
& Married & 14 & 23.4 \\
& Secondary & 05 & 08.3 \\
& Ordinary National Diploma & 07 & 11.7 \\
& National Certificate in Education & & \\
& & 05 & 08.3 \\
& Higher National Diploma & 15 & 25.0 \\
& First Degree & 08 & 13.3 \\
& Master's Degree & 06 & 10.0 \\
\hline
\end{tabular}

Lekki community having been developed to an extent as a result of Environmental Education now experiences an influx of companies and investors leading to construction of good drainages (Figure 1) in contrast to the dilapidated drainages (Figure 2) formerly present. There is also construction of pedestrian bridges (Figure 3) and new roads (Figure 4) in contrast to the old roads surrounded with vegetation (Figure 5); which reduced the rate of traffic jams and accidents. Toll gates (Figure 6) were constructed in Lekki which serve as a source of revenue to the government. These are in agreement with the findings of Agbogidi and Ofuoku (2007) that the environment needs to be sustainably managed in order to fight against some of the consequences of environmental degradation.

Masts were erected by telecommunication companies which improved communication and access to internet in Lekki. Most of the companies there are using wind turbines to generate power instead of depending on the nation's epileptic power supply and wastes are also better managed. These are in agreement with the findings of Kwale and Wageti (2005) that Environmental Education and protection is inevitable in Nigeria, if actually it wants to achieve environmental sustainability for self-reliance and positive development.

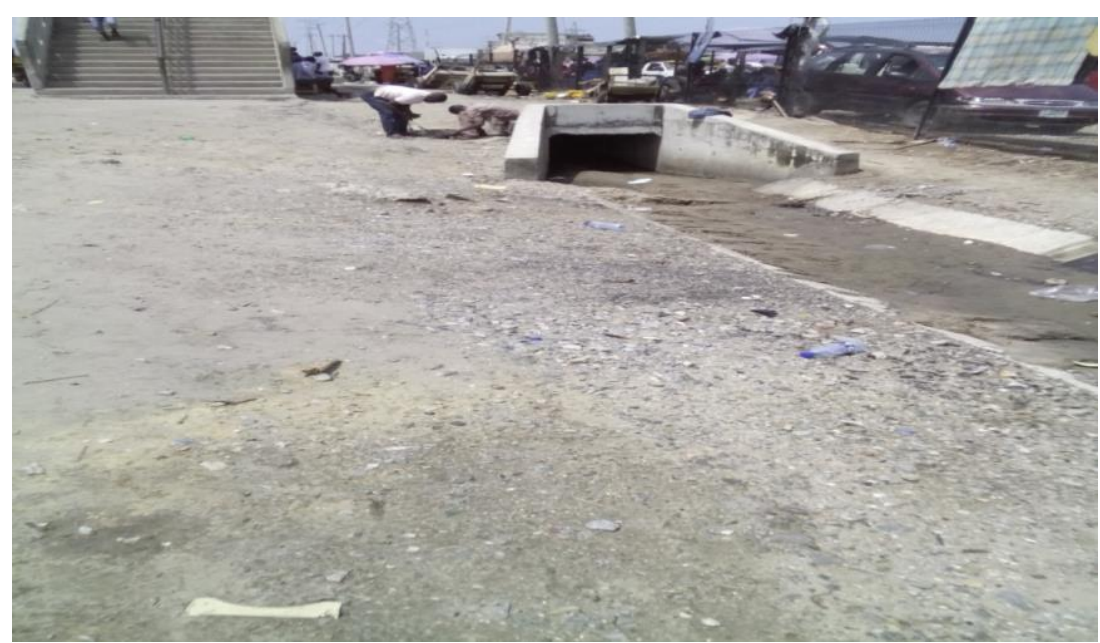

Figure 1: A good drainage system under construction 


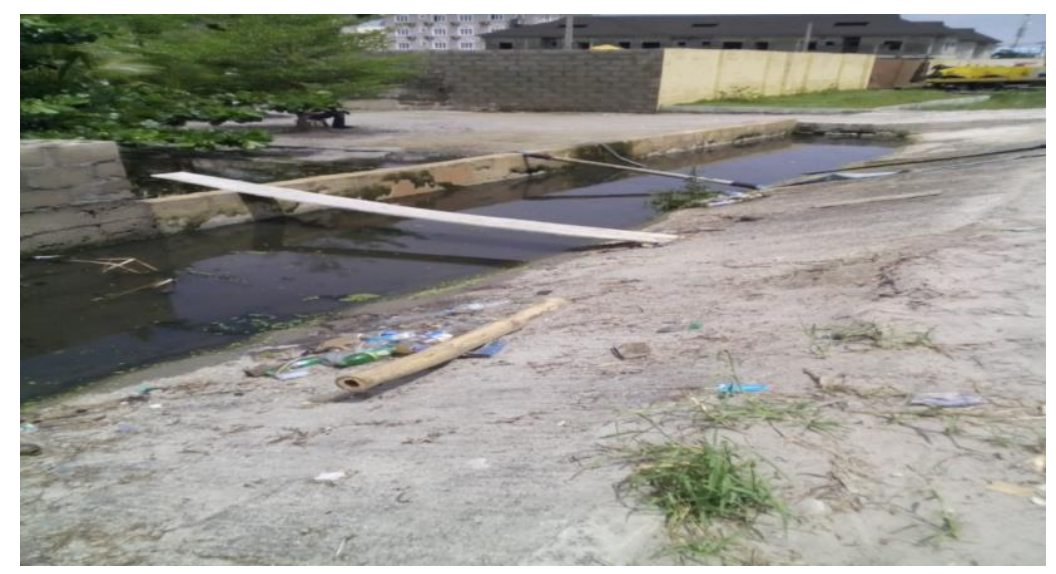

Figure 2: A dilapidated drainage system

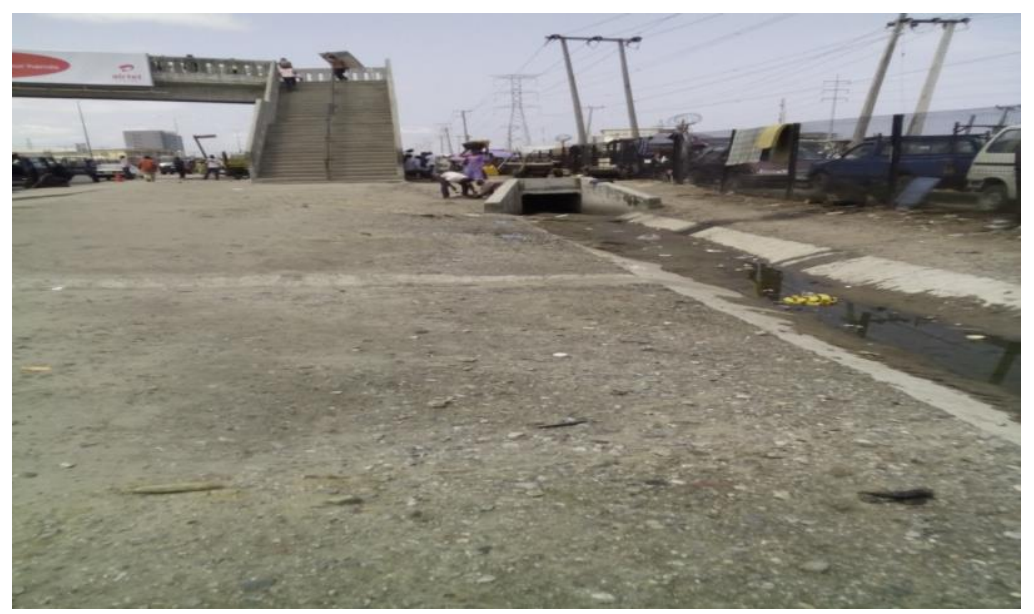

Figure 3: A pedestrian bridge

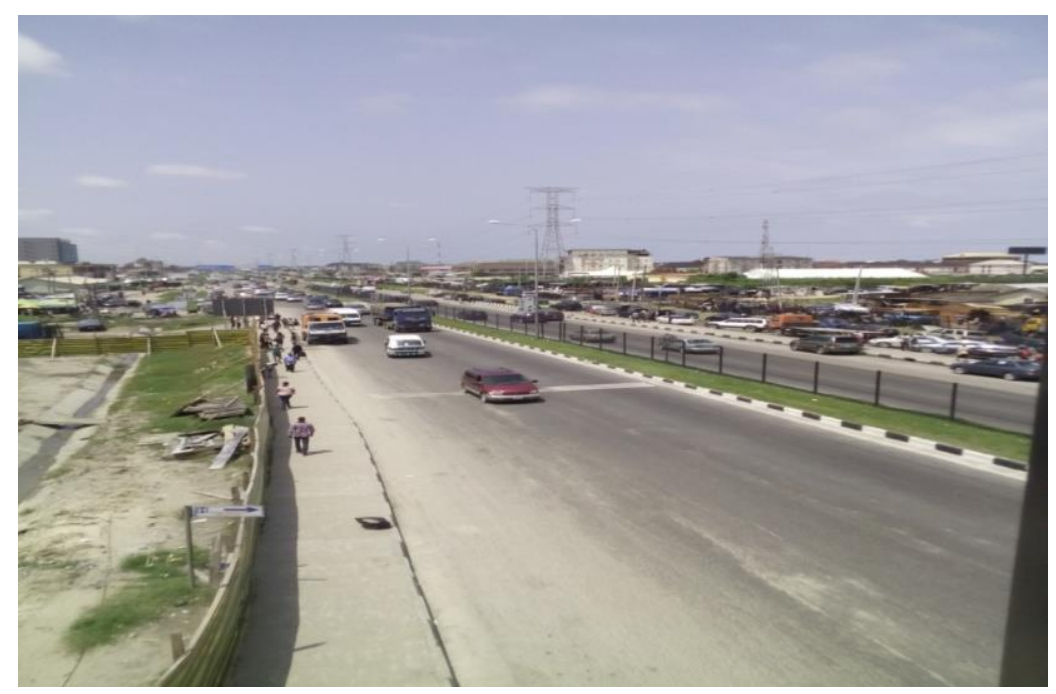

Figure 4: A newly constructed road 


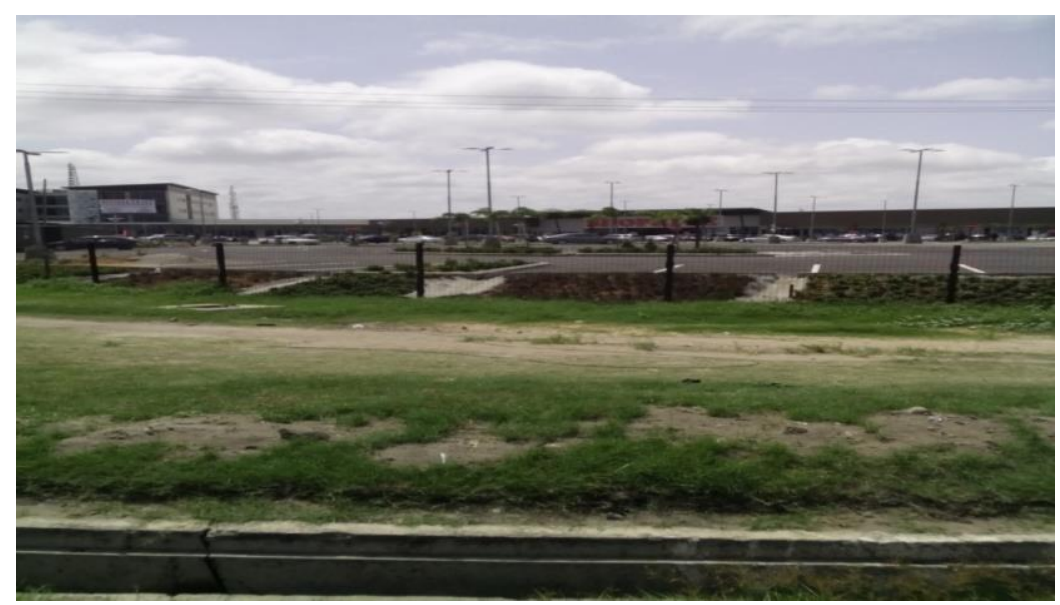

Figure 5: A road surrounded with vegetation

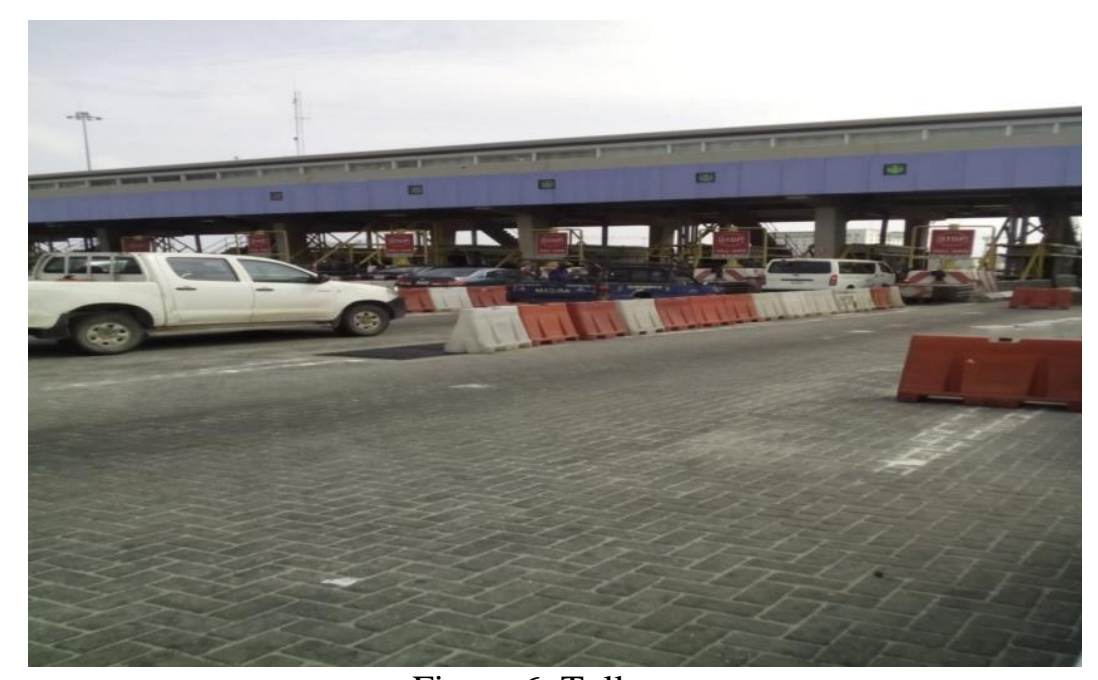

Figure 6: Toll gate

Table 2: Paired t-test for Pre-test and post-test means on the EE-DQ

\begin{tabular}{lcccccc}
\hline EE-DQ & Mean & $\mathrm{N}$ & $\mathrm{SD}$ & Mean difference & $\mathrm{t}$ & Significance(two-tailed) \\
\hline Pre-test & 33.2 & 60 & 18.06 & -47.2 & 1.67 & 0.05 \\
Post-test & 80.4 & 60 & 10.40 & & & \\
\hline
\end{tabular}

*significant at 0.05 level of significance; $\mathrm{SD}=$ Standard Deviation

A pre-test mean of $33.2(\mathrm{SD}=18.06)$ and post-test mean of $80.4(\mathrm{SD}=10.40)$ were recorded on the EE-DQ. The mean difference was 47.2 (Table 2). The results from the paired sample comparison of the means differed significantly $\left(\mathrm{t}_{60}=1.67, \mathrm{p}=0.05\right)$. Generally, the present state of Lekki differed significantly from that before the intervention of public-private practice in developing the area $(\mathrm{P}<$ $0.05)$.

\subsection{Conclusions}

Environmental Education impacted positively in developing the community. Lekki now serves as an example of sustainability. It is thus recommended that environmental Education should be intensified in Lekki. The government and other stakeholders should also collaborate on a higher scale to enhance developing the unreached communities. 


\section{References}

Abubakar, U.I. (2010). Teaching environmental education through Geography studies in senior secondary school. The Dulbuni Journal of Educational Research, 1(4), pp. 176-183.

Agbogidi, O. M. and Ofuoku, A. U. (2007). Promoting environmental protection in Nigeria through environmental education: the role of women. Journal of Environmental Extension, 6 (1), pp. 17-24.

Agbu, O. (2005). 'Oil and Environmental Conflicts', in Salihu, H. A (Edited) Nigeria under Democratic Rule (1999-2003): Vol. 2, Ibadan University Press.

Akintude, S.A. (2008). Environmental education and sustainable development in Nigeria; in J.S Babatolu and G. Ikuejube (Ed). Perspective on contemporary socio-political and environmental Issues in Nigeria. Ibadan, Alafas Nigeria Company, IP.

Bonnett, M. (2002). Sustainability as a frame of mind and how to develop it. The Trumpeter 18, pp. $1-9$.

Cotton, D. R. E., Warren, M. F., Maiboroda, O. and Bailey, I. (2007). Sustainable development, higher education and pedagogy: a study of lecturers' beliefs and attitudes. Environmental Education Research 13 (5), pp. 579-597.

Gbamenja, P.T. (1998). Science education and the Nigeria environment. A paper presented at the conference on science education and the future of the Nigerian environment at the federal college of education (technical) Omoku. 9th November

Grodzinska-Jurczak, M., Stepska, A., Nieszporek, K. and Bryda, G. (2006). Perception of Environmental Problems among Pre-school Children in Poland. International Research in Geographical and Environmental Education, 15(1), pp. 62-76

Hill, R. (1999). Environmental education for a sustainable future national action plan. Australia: Commonwealth press.

ICSE. (2000). International Council for Science and the Environment: Recommendations for Improving the Scientific Basis for Environmental Decision Making.

Jekayinfa, A.A. and Yusuf, A.R. (2008). Teacher's opinions on the incorporation of environmental education in the Nigerian primary school curriculum. Education Research and Review, 3(11), pp. 334338.

Kwale, M.J. and Wageti, H.W. (2005). The Nigerian vegetation; its influence on the environment and contribution to the national economy. Journal of the National Association for Science, Humanities and Educational Research, 4(3), pp.76-81

Le Grange, L. (2012a). Why we need a language of (Environmental) Education. In Stevenson R, Brody M, Dillon J \& Wals AEJ (eds). International Handbook of Research in Environmental Education, New York, Routledge.

Le Grange, L. (2012b). The politics of needs and sustainability education in South Africa. In Stevenson R, Brody M, Dillon J \& Wals AEJ (eds). International Handbook of Research in Environmental Education, New York, Routledge.

Maplandia (2017). Lekki Map - Satellite Images of Lekki. [Online] Available at: http://www.maplandia.com/nigeria/lagos/ibejulekki/lekki/ [Accessed 13 April 2017]

Moseley, C. (2000). Teaching for environmental literacy. Clearing House, 74(1), pp. 23-25. 
Saka, L., Salihu, H. A., Ali, A. A. (2007). Environmental Degradation, Rising Poverty and Conflicts: Towards an Explanation of the Niger Delta Crisis. Journal of Sustainable Development in Africa, 9(4), pp.275-290.

Sauvé, L. (1996). Environmental education and sustainable development: A further appraisal. Canadian Journal of Environmental Education 1: pp.7-35.

Telfer, D. J. and Sharpley, R. (2008). Tourism and development in the developing world. New York: Routledge.

Tuncer, M. and Erol, D. (2007). The environmental education in turkey: Some views and

Proposals of biopolitics. http://www.biopolitics.gr/BIOPOLITICS/HTML/PUBS/VOL4/fe-tunce.htm 